\title{
Organizational and economic aspects of innovation management in agro-industrial enterprises
}

\author{
Vladislav Anichin*, Dmitry Chugay, Galina Khudobina, and Natalia Yakovenko \\ Belgorod State Agrarian University named after V. Gorin, 1, Vavilova Street, Mayskiy, Belgorod region, 308503, Russia
}

\begin{abstract}
The economic aspects of innovation activity are determined by the fact that innovations serve to achieve the economic goals of the enterprise, act as a means of competition and require the use of economic resources. When organizing innovation activities, it is important to take into account macroeconomic factors and intra-company conditions. The authors identify three largescale macroeconomic factors that have a significant impact on the chain of interrelated innovations in the activities of modern Russian agro-industrial enterprises. At present, the factor of creating institutions of the digital economy is beginning to take effect, in connection with which the third wave of organizational, technological and marketing innovations and the next growth of agroindustrial production in Russia are expected. Due to the different rates of economic concentration in the three areas of the agro-industrial complex, historically, unfair vertical competition has been and remains one of the limitations for innovation at agro-industrial enterprises. In the digital economy, information about the essential conditions of concluded transactions becomes available to antimonopoly authorities in real time, which allows them to quickly develop and apply regulatory actions in cases of violations of antimonopoly legislation or in cases of "failures" of the market. It is also possible to create institutions that support fair competition in the vertical and horizontal dimensions. The opportunities that open up actualize the improvement of the conditions for innovation activity at the intra-company level.
\end{abstract}

\section{Introduction}

The economic nature of innovation lies in the desire and possibility of obtaining a significant effect from various types of innovations initiated by entrepreneurs, managers and innovators. The intensity of innovation activity at the enterprise level is influenced by two constant factors: the competitive status of the firm and the availability of investment resources. The greatest intensity of innovation activity takes place in those organizations that are simultaneously in a highly competitive environment and have the resources to introduce innovations. Many agro-industrial enterprises belong to such organizations in modern Russia.

Competition encourages the search for new technological, organizational and marketing solutions, and investment resources allow them to be implemented. A balanced combination of motivations and opportunities is ideal. Of course, in addition to investment, opportunities for innovation are also determined by relevant information [1] and the availability of qualified and proactive personnel who are able to justify and implement effective innovations [3].

Macroeconomic conditions, including state and regional policies, play an important role in the activation of innovative activities of agro-industrial enterprises [4, 10]. At the micro level, the organizational and economic mechanism created and regulated by the management of agro-industrial enterprises is of crucial importance $[6,8$, 9].

The link between macroeconomic factors and intrafirm conditions of innovation activity is the economic relations between related enterprises in the value chains, for example, between a beet-growing organization and a sugar factory, between a sugar factory and a trading enterprise. The development of these relations acts as a kind of business background that allows economic entities to implement external and internal prerequisites for innovation. Conversely, the low level of interaction, the lack of prospects for mutually beneficial cooperation can serve as a bottleneck that restricts innovation activity.

At the same time, you should not ignore the individual characteristics of people who develop and implement innovative solutions. Entrepreneurs, managers, and ordinary performers are not always guided by the motives of profit in their behavior. Moral and religious principles, cultural traditions, political sympathies, and individual development plans play an important role [5]. As J. Schumpeter noted on this occasion "First of all, there is a dream and the will to find a private kingdom ..., also a dynasty... Then there is the will to conquer: the impulse to fight, to prove oneself superior to others, to succeed for the sake, not of the fruits of success, but of success itself...Finally, there is the joy of creating, of getting things done, or simply of exercising one's energy and ingenuity" [7]. One way or

* Corresponding author: vladislavanichin@ rambler.ru 
another, innovation serves the interests of the majority of people. However, these same interests in a certain part of them may prevent the introduction of effective innovations or promote the introduction of innovations with low efficiency. Therefore, innovation management will always be an art of compromise between the possibility of obtaining current and future income, between the interests of the owners of the enterprise and the interests of management, employees and public interests.

\section{Main findings of the study}

\subsection{Macroeconomic factors of innovation activity}

In dynamics, innovation activity can be represented as a growing and branching graph, the vertices of which are certain innovations (including technological, organizational and marketing), and the edges are paired causal relationships, since any innovation inevitably generates the next one. So, at one time, the conveyor (technological innovation) caused organizational innovations in the automotive industry, which provided mass production of cars. Relatively affordable and numerous assembly line vehicles (product innovation) have catalysed new sales and service methods (marketing innovation) and new economic activities, including road construction, oil production, and refining. The rules of the road acted as an organizational innovation. The subsequent improvement of conveyor technology is largely due to the development of robotics...

Similar dynamic innovation graphs are being developed in other sectors of the economy, including the agro-industrial complex. So, after the introduction of single-sprouted varieties of sugar beet, precision seeding drills and the rejection of manual labor in the care of crops became relevant in beet production. As a result, labor productivity in the cultivation of sugar beet has increased more than 10 times.

The intensity of innovation activity of agro-industrial enterprises is greatly influenced by macroeconomic factors, some of which are macro-innovations of the organizational type.

As applied to modern Russia, the initial vertex of the first dynamic innovation graph was the introduction of the institutions of entrepreneurial activity and private ownership of the means of production (Figure 1).

This was followed by the privatization of most industrial and agricultural enterprises. New owners, as a rule, initiated technological innovations, mainly process innovations, and also began to actively introduce organizational innovations in equipping workplaces, managing production and coordinating the activities of related enterprises. Currently, large agro-industrial formations (mainly agricultural holdings) make a decisive contribution to ensuring food security in Russia. In the Belgorod region in 2019 agro-industrial formations produced $68.8 \%$ of the total volume of agricultural products.

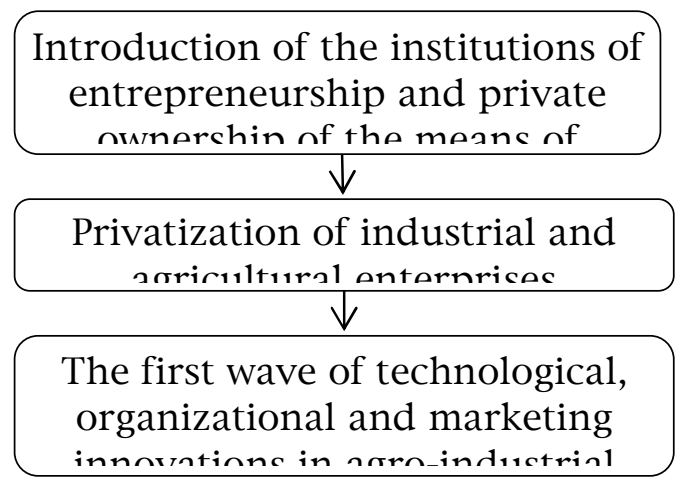

Fig. 1. The first dynamic innovation graph of the Russian agroindustrial complex

The regions of the Russian Federation, where the processes of agro-industrial integration have developed most intensively, are currently the leaders in terms of the volume of production of agri-food products in the country. For example, the Belgorod region, despite the fact that in 2019 it had only $1.79 \%$ of the sown area of Russia, produced $4.58 \%$ of gross agricultural output (the ratio of the share in gross production to the share in the total area of crops is 2.56). The region's share in the production of livestock and poultry for slaughter is $12.62 \%$, and in the volume of net profit of agricultural organizations in Russia $-27.1 \%$.

In recent years, an effective catalyst for innovation in the agro-industrial complex has been the embargo on food imports to Russia (forced organizational innovation in response to anti-Russian sanctions). Restrictions on the import of food products caused an increase in investment in the Russian agro-industrial complex and subsequent innovations of various types at the micro level (Figure 2).

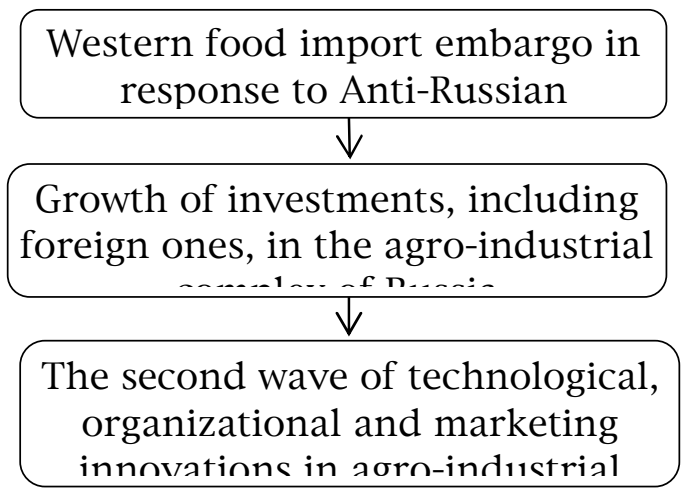

Fig. 2. The second dynamic innovation graph of the Russian agro-industrial complex

Any innovation sooner or later exhausts its potential and turns into a routine. Therefore, the next growth of agro-industrial production in Russia is expected from the creation of digital economy institutions (Figure 3).

Historically, unfair vertical competition has been and remains one of the constraints on innovation at agroindustrial enterprises. Unfair vertical competition occurs between related enterprises in value chains and is 
expressed either in overcharging if the seller has more market power, or in undercharging if the buyer has more power. The noted historical pattern is due to different rates of economic concentration in the areas of the agroindustrial complex (production of means of production, production of agricultural products, processing of agricultural products), as well as in the field of wholesale food trade. Producers of the means of production (such as seeds and fertilizers) and wholesale buyers of food have the greatest market power.

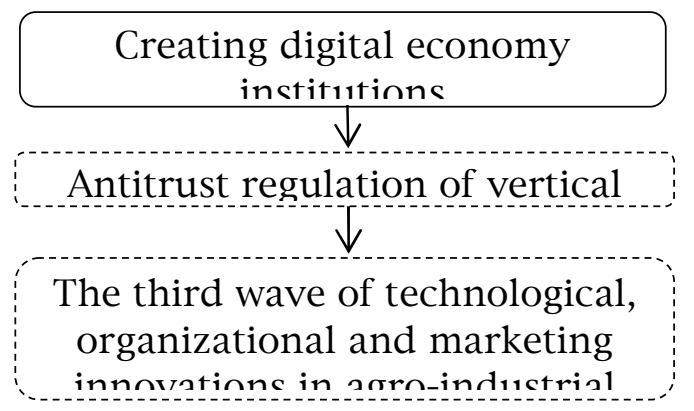

Fig. 3. The third (expected) dynamic innovation graph of the Russian agro-industrial complex

Inequality in market power is also evident in the interaction of organizationally independent agricultural and processing enterprises. The costs of unfair vertical competition here are largely offset by the creation of agro-industrial formations, in which the interaction of related enterprises in the value chains is regulated at the holding level.

One of the most important advantages of the digital economy is that information about the essential conditions of concluded transactions becomes available to antimonopoly authorities in real time, which allows them to quickly develop and apply regulatory actions in cases of violations of antimonopoly legislation or in cases of "failures" of the market. In addition, it becomes possible to create institutions that support fair competition in the vertical and horizontal dimensions.

Such an institution can be a pulling system of commodity movement [2], which ensures fair pricing, a combination of competition and centralized distribution of quotas for production and sales of products. It is quite appropriate in the beet-sugar, dairy-food and a number of other subcomplexes of the agro-industrial complex.

In the digital economy, it becomes possible to measure the market power of any economic entity that carries out official transactions. The market power of an enterprise should be evaluated comprehensively, taking into account its position in the market as a seller and buyer. To measure this phenomenon, the market power index is suitable, calculated using the formula:

$$
I p=S / F C \times C / F S
$$

where $S$ is the number of possible suppliers of raw materials or finished products for the $i$-th enterprise;

$F C$ - number of buyers of raw materials or finished products from suppliers of the $i$-th enterprise (the total number of competitors of the $i$-th enterprise in the procurement market);
$C$ - number of buyers of products from the $i$-th enterprise;

$F S$ - number of sellers whose products are purchased by the buyers of the products of the $i$-th enterprise (the total number of competitors of the $i$-th enterprise in the sales market).

For example, the $i$-th bakery is offered to supply flour to twenty organizationally independent enterprises $(S=20)$. These same suppliers sell flour to ten organizationally independent bakeries (including the I-th bakery) and six other wholesale customers $(F C=10+6=16)$. The $i$-th bakery supplies its products to twelve organizationally independent retailers $(C=12)$. These retailers purchase bakery products from ten organizationally independent enterprises, including the $i$ th bakery $(F S=10)$.

Therefore, the market power index of the $i$-th bakery is equal to:

$$
\text { Ip }=20 / 16 \times 12 / 10=1.5 .
$$

For the $i$-th retailers (one of 12, having the opportunity to purchase 10 of bakery enterprises) that implements the bakery one thousand buyers $(C=1000)$, which can buy these products from five retailers $(F S=5)$, the index of market power is:

$$
\text { Ip }=10 / 12 \times 1000 / 5=166.7 \text {. }
$$

Such differences in the market power of related enterprises largely determine the unequal distribution of income between them, which generally creates problems for the implementation of innovation activities.

\subsection{Intra-company conditions of innovation activity}

In addition to macroeconomic factors, the intensity of innovation activity in agro-industrial enterprises is greatly influenced by the organizational and economic conditions formed at the micro level. Unlike macroeconomic factors, these conditions can be changed at the will and desire of the company's stakeholders.

Innovation activity in agro-industrial enterprises has two main aspects. The first is associated with the introduction of effective innovations at the initiative of the owners and management of the enterprise. The second-with the management of innovative activity of human resources available to the agro-industrial enterprise. The second aspect has two directions: 1) mass innovation creativity; 2) a single, but more focused and large-scale innovative proposal, which is, in fact, the initiation of an investment project (Figure 4).

Effective management of mass innovation activity is achieved by the implementation of the following organizational and economic measures: 1) formation and maintenance of the corporate database of innovation proposals; 2) development and application of the procedure for consideration of innovation proposals and material remuneration of innovation activity; 3 ) creation of a production and technical commission for the evaluation of innovation proposals and organization of its work.

The database of innovation proposals should include information about the authors of rationalization 
proposals, the content of rationalization proposals, the terms of their submission and consideration, information about the conclusion of the production and technical commission, a description of the results of implementation, the amount and nature of remuneration to the authors of rationalization proposals. The size and nature of the royalties should be commensurate with the beneficial effect of the implementation of the rational offer. The composition of the production and technical commission should be selected from specialists who are able to perform work on the assessment of the technical and economic efficiency of the innovation proposal.

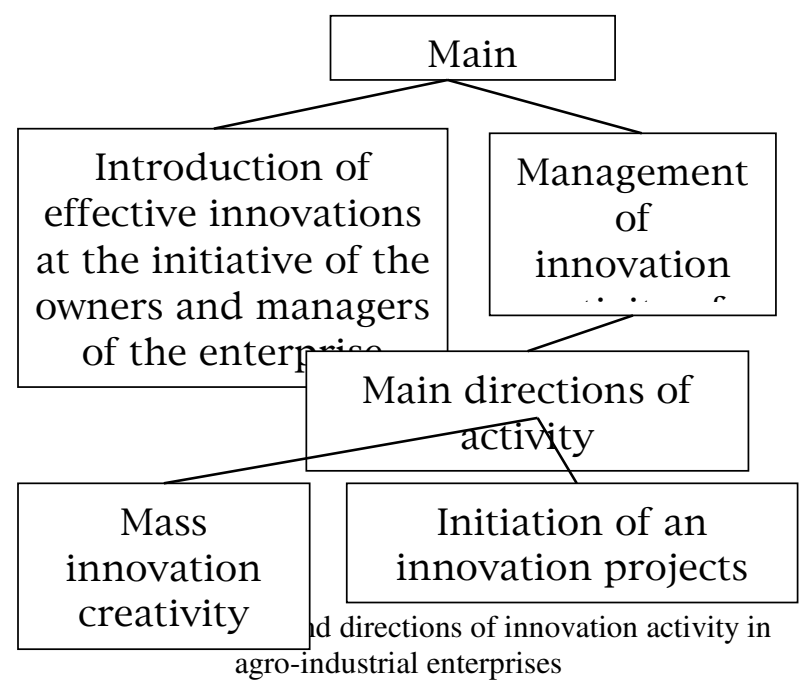

Most agro-industrial enterprises grow dozens of crops and several types of farm animals. In addition to the main business units, many of them have industrial and auxiliary production facilities. For such multiindustry enterprises, there is always the problem of choosing the optimal combination of activities.

Quantitatively, the combination of industries can be expressed by the distribution of resources between activities, in particular, the structure of acreage. This is true for both an agricultural enterprise and an enterprise that combines the production of agricultural products and their processing.

Despite the fact that the rational composition of industries is one of the conditions for the efficiency of agro-industrial production, the variety of technological solutions in each of the industries creates the problem of choosing the product and technological structure of the enterprise.

This choice should ideally give an answer to the question of which crops, in what ratio, what technologies should be grown, how to use the resulting crop and livestock products, taking into account the available technologies of on-farm processing, in order to ensure the achievement of agribusiness goals in a particular enterprise.

The choice of an effective product and technological structure of the enterprise is possible if:

1) there is a political will of the management entity (owners and management of the agro-industrial enterprise) to take actions to improve the management object;
2) management entity has information about all economically significant costs and results of production and commercial activities in the controlled links of the value chain (starting from crop production units and ending with units for the production of consumer products and their marketing);

3 ) consistent target indicators have been formed that allow for the targeted selection of the product and technological structure of the enterprise;

4) optimization or heuristic methods are available that allow you to quickly get the desired parameters of the product and technological structure of the enterprise;

5) organizational and managerial measures for goal setting, delegation of authority and distribution of responsibility between managers and specialists have been implemented.

Together, these five conditions represent the organizational and economic mechanism of innovative activity of an agro-industrial enterprise.

\section{Conclusion}

The intensity and content of innovative activity of agroindustrial enterprises are determined by macroeconomic factors and intra-company conditions. Economic relations between related enterprises in value chains play an important connecting role. The differences in market power between producers of the means of production, agricultural, processing and commercial enterprises are so great that it significantly affects the level of prices and the distribution of income. The excess profits of some counterparties and the lack of funds of others equally, but for various reasons, reduce the intensity of innovation activity. Agro-industrial integration only partially solves this problem. Significantly greater opportunities are provided by the institutions of the digital economy. One of them can be a pulling system of commodity movement, which ensures fair pricing, a combination of competition and a centralized distribution of quotas for the production and sale of products.

When organizing innovation activities at the enterprise level, it is important to proceed from the fact that innovation is not only an implemented novelty, but first of all a useful novelty. The utility criteria are set by the owners and managers of the enterprise, based on their own economic and other goals. Therefore, the effectiveness of the organizational and economic mechanism of innovation activity will primarily depend on the quality of goal setting.

An equally important aspect is how to ensure the coherence and reliability of the innovation mechanism. Often, expensive technological innovations are promoted by manufacturers of agricultural machinery and industrial equipment. Dealers use various marketing techniques, including sales promotion. Under the pressure of such a proposal, the right decision is not always made by the management of the agro-industrial enterprise. Therefore, further research on the development of the "anti-corruption" component of the innovation mechanism will be relevant. 


\section{References}

1. V. Alt, S. Isakova, E. Balushkina, Selection of crop technologies: approaches and methods applicable in information systems, Vestnik of Kazan state agrarian university, 1, 52-58, (2020)

2. V.L. Anichin, Regulation of vertical competition as the means of modernisation of the agro-industrial complex, The problems of economy, 1 , 28-33 (2013)

3. V.L. Anichin, Yu.Yu. Vashcheykina, G.I. Khudobina, N.Yu. Yakovenko, Innovations in the personnel management of an agricultural enterprise, Advances in Economics, Business and Management Research, 157, 209-214 (2020)

4. K.A. Kalashnikov, A.P. Shindryaeva, The role of innovation in the development of agroindustrial complex, Journal of international economic affairs, 2, 10611070 (2019)

5. R. Kapinos, A. Dobrunova, O. Akupiyan, D. Kravchenko, Distinctive features of classification of factors determining the economic behavior of economic entities predominantly rural areas from the standpoint of the theory of long waves, International Review (3-4) 26-34, (2018)

6. S.A. Saninsky, K.A. Kalashnikov, Formation of the mechanism for the implementation of innovations in the production and economic activities of agricultural enterprises, Problems of Contemporary Science and Practice. Vernadsky University, 3, 79-87 (2019)

7. J.A. Schumpeter, The Theory of Economic Development: An Inquiry into Profits, Capital, Credit, Interest and the Business Cycle, (New Brunswick (U.S.A) and London (U.K.): Transaction Publishers, 2008)

8. F. Suboch, Study of the levers and mechanisms that form the potential for innovative development of enterprises of the agroindustrial complex, Agricultural economy, 8, 3-23 (2019)
9. I. Yasnolob, Ya. Radionova, The organizational fundamentals of innovation development management of agro-industrial enterprises, Economics, Management and Sustainability, 2 (1), 60-66. (2017)

10. Yu. I. Zdorovec, O.V. Goncharenko, Characteristics and trends of development of agrarian production of the holdings in Belgorod region, Scientific notes of the Russian academy of entrepreneurship, 49, 296-308 (2016) 